\title{
INDUÇÃO DE RESISTÊNCIA E QUALIDADE PÓS-COLHEITA DE AMORA-PRETA TRATADA COM ÁCIDO SALICÍLICO ${ }^{1}$
}

\author{
FABIANA CHIAMULERA BORSATTI², SÉRGIO MIGUEL MAZARO ${ }^{3}$, \\ MOESES ANDRIGO DANNER ${ }^{3}$, GILMAR ANTÔNIO NAVA ${ }^{3}$, NEAN LOCATELLI DALACOSTA ${ }^{4}$
}

RESUMO-O objetivo deste trabalho foi avaliar o efeito do elicitor ácido salicílico (AS) aplicado em póscolheita de amora-preta sobre a conservação e a indução de resistência. Foram colhidas amoras da cultivar Tupy selecionadas e submetidas ao tratamento em diferentes concentrações de AS $(0,5 ; 1,0 ; 1,5$ e 2,0 mM) e a testemunha (água destilada). Utilizou-se do delineamento experimental inteiramente casualizado, com quatro repetições de 30 frutos por unidade experimental. Após 144 horas de armazenamento, na temperatura de $8^{\circ} \mathrm{C}$, avaliaram-se a perda de biomassa fresca, os teores de sólidos solúveis totais (SST), a acidez total titulável (ATT) e de ácido ascórbico, bem como a incidência de podridões. Nos intervalos de 24; 48; 96 e 144 horas, retiraram-se amostras de frutos para determinação de proteínas totais, antocianinas, flavonoides e atividade das enzimas fenilalanina amônia-liase (FAL), quitinases e $\beta$-1,3-glucanase. Houve aumento do teor de proteínas e ativação da $\beta$-1,3-glucanase com a aplicação de $\mathrm{AS}$, demonstrando haver indução de resistência nos frutos pela aplicação de AS. Os teores de antocianinas e flavonoides, bem como a atividade da FAL, tiveram alterações no decorrer do experimento, em função da aplicação de AS, demonstrando haver ativação da rota dos fenilpropanoides para síntese de metabólitos secundários. Os tratamentos de AS não afetaram os parâmetros de perda de biomassa fresca, AT, SST, incidência de podridões, ácido ascórbico e atividade de quitinase.

Termos para indexação: Rubus sp., fenilalanina amônia-liase, quitinase e $\beta$-1,3-glucanase, antocianinas e flavonoides.

\section{INDUCTION OF RESISTANCE AND POST-HARVEST QUALITY OF BLACKBERRY TREATED WITH SALICYLIC ACID}

\begin{abstract}
The objective of this study was to evaluate the effect of the elicitor salicylic acid (SA) applied in post-harvest blackberry on conservation and the induction of resistance. Blackberry cultivar Tupy fruits were harvested, selected and subjected to treatment with different concentrations of SA $(0.5,1.0,1.5$ and $2.0 \mathrm{mM})$ and control (distilled water). We used a completely randomized design with four replications of 30 fruits per experimental unit. After 144 hours storage at the temperature of $8{ }^{\circ} \mathrm{C}$, it was evaluated the weight loss, total soluble solids (TSS), titratable acidity (TA), ascorbic acid and the incidence of rottenness. At intervals of 24 , 48, 96 and 144 hours fruit samples were withdrew for determination of total protein, anthocyanins, flavonoids and activity of the enzymes: phenylalanine ammonia-lyase (PAL), chitinase and $\beta$-1,3-glucanase. There was an increase of protein content and activation of $\beta$-1,3-glucanase with the application of SA, demonstrating induction of resistance in fruits by application of SA. The content of anthocyanins and flavonoids, as well as the activity of PAL, had changes during the experiment due to the application of SA, which demonstrated activation of the phenylpropanoid route for synthesis of secondary metabolites. The treatments of AS did not affect the mass loss, TA, TSS, rot incidence, ascorbic acid and chitinase activity.
\end{abstract}

Index terms: Rubus sp, phenylalanine ammonia lyase, chitinase and $\beta$-1,3-glucanase, anthocyanins and flavonoids.

${ }^{1}$ (Trabalho 087-14). Recebido em: 28-02-2014. Aceito para publicação em: 25-09-2014.

${ }^{2}$ Mestranda do Programa de Pós Graduação em Agronomia da Universidade Tecnológica Federal do Paraná (UTFPR), Caixa Postal 571, CEP: 85.501-970, Pato Branco - PR. E-mail: fabianaborsatti@gmail.com;

${ }^{3}$ Eng. Agr., Dr., Prof. de Agronomia, UTFPR, Caixa Postal 157, CEP: 85660-000, Dois Vizinhos - PR. E-mail: sergio@utfpr.edu.br; moesesandrigo@yahoo.com.br; gilmarnava@utfpr.edu.br;

${ }^{4}$ Acadêmico de Agronomia, UTFPR, Caixa Postal 157, CEP: 85660-000, Dois Vizinhos - PR. E-mail: nean.locatelli@hotmail.com;

Rev. Bras. Frutic., Jaboticabal - SP, v. 37, n. 2, p. 318-326, Junho 2015 


\section{INTRODUÇÃO}

A amoreira-preta (Rubus spp) ainda é uma espécie frutífera pouco cultivada no Brasil, mas apresenta elevado potencial, por ser rústica e de alta produção. Além disso, a amora-preta é uma fruta que possui sabor marcante e com propriedades antioxidantes (VIZZOTTO et al., 2012), o que representa elevado potencial de comercialização. No Brasil, ocorrem cinco espécies nativas de amoras, mas nenhuma destas foi domesticada, sendo que as cultivares comerciais de amoreira-preta utilizadas são resultado de introduções, hibridações e seleções de cultivares dos Estados Unidos. Dentre estas, destacase a Tupy, sendo a mais cultivada no Brasil, que foi lançada em 1988, pela Embrapa Clima Temperado (RASEIRA et al., 2008).

Porém, a amora-preta é muito perecível, tendo rápida perda de qualidade em pós-colheita, sendo, por isso, mais utilizada para transformação em geleias e outros subprodutos.

Elicitores são produtos de origem biótica ou abiótica que, quando aplicados em plantas, induzem a expressão de genes que codificam diversas respostas de defesa a patógenos, conduzindo à indução da resistência sistêmica adquirida (RSA). A RSA promove a proteção de tecidos da planta ainda não atacados, tornando-os resistentes à infecção por patógenos. Tais respostas de defesa incluem síntese de proteínas relacionadas à patogenicidade (proteínas-RP), dentre as quais as quitinases e glucanases, aumento da atividade de peroxidases e da enzima fenilalanina amônia-liase, envolvida na rota de síntese de compostos fenólicos e acúmulo de lignina em tecidos adjacentes ao local de penetração do patógeno (DURRANT;DONG, 2004).

O ácido salicílico (AS) é um elicitor que tem um extensivo papel de sinalizador em plantas, especialmente na defesa contra patógenos, sendo transportado via floema para as partes não infectadas da planta, principalmente na forma de metilsalicilato e, inclusive, servindo de sinal para plantas vizinhas. Pesquisas com plantas com genes mutados demonstram que o AS regula mecanismos de resistência no local de infecção (resposta de hipersensibilidade - HR) e através da RSA, atuando na expressão de genes responsáveis pelo acúmulo de espécies reativas de oxigênio no apoplasto, tais como superóxido $\left(\mathrm{O}_{2}^{-}\right)$e peróxido de hidrogênio $\left(\mathrm{H}_{2} \mathrm{O}_{2}\right)$, que causam a morte de células no local da infecção (HR), pela síntese de lignina na parede celular de células vizinhas ao local de infecção e pela síntese de proteínas-RP e compostos fenólicos em locais distantes da infecção (RSA) (GRÜNER et al., 2003;
JALALI et al., 2006; VLOT et al., 2009).

A aplicação de elicitores está sendo testada para aumentar a conservação de frutos, pois atuam na ativação de mecanismos de defesa vegetal, como os observados pela aplicação de AS em pós-colheita de morangos (LOLAEI et al., 2012; SALARI et al., 2012) e pêssegos (KHADEMI; ERSHADI, 2013).

Entretanto, por mais que se conheçam no meio científico os efeitos do indutor de resistência $\mathrm{AS}$, os trabalhos ainda são inexistentes para a amora-preta. Neste sentido, o objetivo deste trabalho foi avaliar o efeito do ácido salicílico aplicado na amora-preta em pós-colheita na sua conservação e na indução de resistência sistêmica adquirida.

\section{MATERIAL E MÈTODOS}

As amoras-pretas da cultivar Tupy foram colhidas num pomar experimental do setor de fruticultura da Universidade Tecnológica Federal do Paraná - UTFPR, Câmpus Dois Vizinhos, e imediatamente transportadas e acondicionadas sob refrigeração no laboratório de Fitossanidade da UTFPR, onde foram selecionadas quanto ao tamanho, grau de maturação e ausência de injúrias. Em seguida, foram aplicadas diferentes concentrações de ácido salicílico: 0,$5 ; 1,0 ; 1,5$ e $2,0 \mathrm{mM}$ e a testemunha (água destilada). As amoras ficaram submersas por 1 minuto nos tratamentos e, em seguida, foram acondicionados em bandejas de isopor com tampa (dimensões de $10 \times 10 \times 8 \mathrm{~cm}$ ). Utilizou-se do delineamento experimental inteiramente casualizado, com quatro repetições (bandejas) de 30 frutos para cada unidade experimental.

Após 144 horas de armazenamento em B.O.D., na temperatura de $8^{\circ} \mathrm{C}$, avaliaram-se a perda de biomassa fresca, os teores de sólidos solúveis totais (SST), de acidez titulável (AT) e de ácido ascórbico, bem como a incidência de podridões. Em intervalos de 24; 48; 96 e 144 horas, retiraramse amostras de cinco frutos para determinação de proteínas totais, antocianinas, flavonoides e atividade das enzimas fenilalanina amônia-liase, quitinase e $\beta$-1,3-glucanase. Tais análises foram realizadas para todos os tratamentos, com exceção de quitinase e $\beta$-1,3-glucanase que foram realizados somente para os tratamentos-testemunha e na maior concentração $(2,0 \mathrm{mM})$.

A perda de biomassa fresca das amoras foi obtida pela diferença de biomassa do dia da instalação do experimento e do valor encontrado na pesagem após 144 horas de armazenamento, expresso em percentual. O teor de SST foi analisado do suco 
extraído dos frutos, com o auxílio de um extrator manual, e mensurado com auxílio de um refratômetro digital. Os valores foram expressos em ${ }^{\circ}$ Brix. A acidez total titulável (ATT) foi determinada de 10 $\mathrm{mL}$ de suco dos frutos diluído em $90 \mathrm{~mL}$ de água destilada, seguido por titulação com uma solução de hidróxido de sódio $0,1 \mathrm{~N}$ até atingir $\mathrm{pH} 8,1$, sendo expresso em meq $100 \mathrm{~mL}^{-1}$. A avaliação da incidência de podridões foi realizada por análise visual e confirmada com auxílio de um estereomicroscópio binocular, e expressa em percentual de frutas com sintomas de doenças (micélios aparentes).

A análise de ácido ascórbico (vitamina $\mathrm{C}$ ) foi realizada por volumetria, com utilização de iodo padronizado para oxidorredução, segundo metodologia do Instituto Adolfo Lutz (2005), em que cada $\mathrm{mL}$ de iodo gasto na titulação corresponde a 8,806 mg de ácido ascórbico. Para a quantificação de proteínas, foi empregado o teste de Bradford (1976), sendo retirado $0,3 \mathrm{~mL}$ do suco das frutas, colocado em um recipiente e adicionados mais 2,5 mL da solução tampão Fosfato 0,2 Molar $\mathrm{pH}$ 7,5 , obtendo-se assim o extrato. Este extrato foi colocado em ependorfes devidamente identificados, levados à centrífuga, onde permaneceram por 10 minutos a $12.000 \mathrm{rpm}$ e a $4{ }^{\circ} \mathrm{C}$. Após retirados da centrífuga, foram transferidos 40 microlitros do extrato sobrenadante para tubos de ensaio, sendo adicionados mais 460 microlitros de água destilada e 1,0 mL do reagente Bio-Rad diluído 1:4. As soluções foram agitadas e, após, acondicionadas em cubetas pra ser realizada a leitura a 630 nanômetros em espectrofotômetro, obtendo-se, assim, o valor de absorbância. Como padrão, foi utilizado soro albumina bovina.

Para a quantificação de flavonoides e antocianinas, utilizou-se da metodologia descrita por Lees e Francis (1972), sendo utilizado $0,3 \mathrm{~mL}$ do suco das amoras-pretas diluído em $5,0 \mathrm{~mL}$ da solução extratora, formada por etanol a $95 \%$ mais $\mathrm{HCl} 1,5 \mathrm{~N}$ na proporção de $85: 15$. Esse extrato foi conservado em tubos de ensaio ao abrigo de luz e à temperatura de $4{ }^{\circ} \mathrm{C}$, por 20 horas. Após este período, o extrato foi filtrado com mais $5,0 \mathrm{~mL}$ da solução extratora citada acima e deixado em repouso em frascos cobertos com papel- alumínio por 2 horas. Depois do repouso, foi retirado $0,5 \mathrm{~mL}$ da amostra com mais $3,0 \mathrm{~mL}$ da solução extratora e acondicionada em tubos de ensaio identificados, que foram agitados, para então proceder à leitura em espectrofotômetro. Para flavonoides, a leitura foi feita a $370 \mathrm{~nm}$, e para antocianinas, a $535 \mathrm{~nm}$, obtendo-se, assim, os devidos valores de absorbância. O conteúdo de antocianinas (mg.g-1 de amostra) foi determinado pela equação: $\mathrm{C}=\mathrm{ABS} / 98,2$, em que: $\mathrm{C}=$ concentração da amostra; $\mathrm{ABS}=$ absorbância; e 98,2 corresponde ao coeficiente de extinção molecular da cianidina-3-glicosídeo.

$$
\text { (mg.g-1 de amostra), }
$$

A determinação da atividade da fenilalanina amônia-liase foi por quantificação colorimétrica do ácido transcinâmico liberado do substrato fenilalanina, conforme metodologia descrita por Kuhn (2007), sendo utilizado $0,5 \mathrm{~mL}$ do suco das frutas com mais $3,0 \mathrm{~mL}$ do tampão TRIS $-\mathrm{HCl}$ $\mathrm{pH} 8,0$. Este extrato foi acondicionado em tubos ependorfe devidamente marcados, que foram levados para a centrífuga por 10 minutos, a $4{ }^{\circ} \mathrm{C}$ e a 6.000 rpm. Após, foi transferida uma alíquota de $200 \mu \mathrm{L}$ para tubo de ensaio identificado, acrescentando-se mais 3,0 $\mathrm{mL}$ do tampão de extração. A solução foi agitada, obtendo-se assim, o extrato enzimático. Deste extrato, $1,5 \mathrm{~mL}$ foi transferido para outro tubo de ensaio, com mais $1,0 \mathrm{~mL}$ do tampão de extração e $0,5 \mathrm{~mL}$ de fenilalanina. Novamente, esta solução foi agitada para homogeneização. E após, os tubos foram incubados em banho-maria por 45 minutos, a $40^{\circ} \mathrm{C}$. Depois de retirados do banho-maria, os tubos foram colocados em banho de gelo por 5 minutos para interromper a reação e assim poder ser feita a leitura em espectrofotômetro a $290 \mathrm{~nm}$.

Para dosagem das atividades de quitinase e $\beta$-1,3-glucanase, as amostras foram maceradas em $2,0 \mathrm{~mL}$ de tampão acetato $100 \mathrm{mM}(\mathrm{pH} \mathrm{5,0),} \mathrm{com}$ posterior centrifugação (20.000 g por $25 \mathrm{~min}$, a -4 $\left.{ }^{\circ} \mathrm{C}\right)$. O sobrenadante foi coletado e utilizado para a avaliação da atividade das enzimas. A atividade enzimática da quitinase foi avaliada através da liberação de fragmentos solúveis de "CMchitin-RBV", a partir de quitina carboximetilada, marcada com remazol brilhante violeta. Para a determinação espectrofotométrica das atividades de $\beta$-1,3-glucanase nos extratos, foi utilizado como substrato solução de carboximetilcurdlan-remazol azul brilhante (CM-Curdlan-RBB $4 \mathrm{mg} \cdot \mathrm{ml}^{-1}$, Loewe Biochemica $\mathrm{GmbH}$ ), de acordo com metodologia desenvolvida por Wirth e Wolf (1992), e com o procedimento descrito por Guzzo et al. (1996).

Os dados foram submetidos à análise de variância $(p \leq 0,05)$ e apresentados usando estatística descritiva (média \pm desvio-padrão) e análise de regressão polinomial, sendo adotado um nível de 5\% de significância, utilizando o programa ASSISTAT (SILVA; AZEVEDO, 2009). 


\section{RESULTADOS E DISCUSSÃO}

Para os parâmetros físico-químicos perda de biomassa fresca, ATT, SST, incidência de podridões e ácido ascórbico, não ocorreram diferenças significativas entre os tratamentos, após 144 horas de armazenamento, apresentando as seguintes médias: 1,80\% de perda de biomassa, 10,87 meq. $100 \mathrm{~mL}^{-1}$ de AT, 9,58 ${ }^{\circ}$ Brix de SST, 2,66 \% de podridões e $8,12 \mathrm{mg} .100 \mathrm{~g}^{-1}$ de ácido ascórbico. A amora-preta é um fruto não climatérico, muito perecível, sendo sua atividade metabólica bastante acelerada em póscolheita, o que pode ter dificultado as observações do efeito do AS sobre as variáveis físico-químicas, considerando a curta vida pós-colheita da fruta. Também, esta deterioração acelerada das frutas poderia ser restringida se fosse utilizada menor temperatura de armazenamento, a qual foi de 8 ${ }^{\circ} \mathrm{C}$ no presente experimento, temperatura esta que buscou simular a temperatura de exposição (balcões refrigerados) utilizada na grande maioria dos mercados. Porém, Antunes et al. (2003) verificaram que a temperatura de $2^{\circ} \mathrm{C}$ proporcionou maior conservação de amoras-pretas das cultivares Comanche e Brazos, até nove dias após a colheita.

Para outros autores, o AS teve efeito de redução da perda de massa e da incidência de fungos, manutenção da firmeza, maior quantidade de vitamina C, maior AT e teor de SST, inibição da respiração e da produção de etileno (que são relacionados à aceleração do apodrecimento de frutos), e não causou efeitos negativos na aparência e no sabor de pêssegos, romãs e morangos, sendo a concentração de $2,0 \mathrm{mM}$ de AS a mais efetiva na manutenção da qualidade destes frutos (AMBORABE et al., 2002; SAYARI et al., 2009; LOLAEI et al., 2012; SALARI et al., 2012; KHADEMI ; ERSHADI, 2013). Para Sayari et al. (2009), que avaliaram o AS em morangos armazenados a $3^{\circ} \pm 1^{\circ} \mathrm{C}$ por 12 dias, considerou-se que a aplicação de AS pode ser boa alternativa na póscolheita de morangos na manutenção dos parâmetros qualitativos e quantitativos, considerando-se sua alta perecibilidade; no entanto, considerou-se que existe comportamento distinto entre as cultivares. Além da melhoria dos parâmetros físico-químicos pela aplicação de AS, os autores Khademi; Ershadi, (2013) armazenaram pêssegos a $0^{\circ} \pm 1^{\circ} \mathrm{C}$, por 7 semanas, com avaliações semanais e consideraram o AS um produto seguro e com grande potencial de utilização na melhoria da qualidade pós-colheita dos frutos.

Os dados demonstraram que houve aumento do teor de proteínas com a aplicação de AS. Após 24 horas da aplicação de AS na concentração de 1,0 mM, ocorreu um pico de ativação da síntese de proteínas, diferindo significativamente dos demais tratamentos. Nos frutos tratados nas concentrações de 1,5 e 2,0 $\mathrm{mM}$ de AS, ocorreu elevação do teor de proteínas de maneira gradual, atingindo o pico máximo com 96 horas após a aplicação, diferindo significativamente dos demais tratamentos. Observa-se que, para o teor de proteínas da testemunha (sem aplicação de AS), há uma elevação com 48 horas, e mantem-se constante até 144 horas (Figura 1).

Também, quando se avaliou a atividade das enzimas quitinase e $\beta$-1,3-glucanase, nos tratamentos-testemunha e na maior concentração (2,0 mM), observou-se que o AS atuou sobre a atividade da $\beta$-1,3-glucanase, ocorrendo ativação da mesma após 48 horas da aplicação dos tratamentos, e diferindo da testemunha com 96 e 144 horas (Tabela 1). Tal resultado sugere que existe uma relação entre a alteração dos níveis de proteínas totais e a atividade da PR-proteína $\beta$-1,3-glucanase, que são ativadas quando se aplica o elicitor AS (DURRANT;DONG, 2004; VLOT et al., 2009). Para a atividade das quitinases, não ocorreu diferença entre os tratamentos, demonstrando haver predominância pela síntese de $\beta$-1,3-glucanase na defesa vegetal (Tabela 1). Os principais componentes da parede celular de muitos fungos são os polissacarídeos quitina e $\beta$-1,3-glucano, que são substratos para a quitinase e a $\beta$-1,3-glucanase, respectivamente (WESSELS; SIETSMA, 1981). Por isso, estas enzimas hidrolíticas são relacionadas à indução da RSA.

Tal resultado demonstrou efeito do AS na ativação de $\beta$-1,3-glucanase e vem corroborar os observados por Inocêncio et al. (2009) em planta de feijoeiro infectada por Sclerotinia sclerotiorum, onde houve um incremento na atividade de $\beta-1,3-$ glucanase nas plantas tratadas com AS.

A atividade da enzima fenilalanina amônia-liase (FAL) foi alterada pela aplicação do AS, demonstrando oscilações no decorrer do armazenamento (Figura 2). Em alguns momentos da avaliação, observou-se comportamento de diminuição da atividade em função dos tratamentos, fato também observado por Picoli et al. (2010), que verificaram redução da atividade da FAL quando aplicaram AS em beterrabas minimamente processadas. Possivelmente, isso tenha ocorrido em função de o AS proporcionar queda na taxa respiratória, reduzindo a formação de fosfoenolpiruvato e de eritrose 4-fosfato, precursores da fenilalanina (substrato da FAL), e diminuindo a atividade desta enzima (ZHANG et al., 2003; PICOLI et al., 2010). Em outros momentos, ocorreu incremento da 
atividade da FAL em função dos tratamentos, como observado em uvas (CHEN et al., 2006) e romãs (SAYARI et al., 2009).

Essa oscilação observada na atividade da FAL, em todos os tratamentos, com o passar do tempo de avaliação, pode estar relacionada à interferência de outros fatores ligados ao metabolismo pós-colheita de frutos que não foram mensurados neste trabalho, tais como a respiração, entre outros.

Quando se aplicou AS nas concentrações de 1,5 e 2,0 mM, os conteúdos de flavonoides foram significativamente menores que na testemunha, até 96 horas depois da aplicação dos tratamentos, superando a testemunha somente na avaliação final, ou seja, após 144 horas da aplicação (Figura 3). Possivelmente, isso se deve ao fato de os tratamentos terem reduzido o metabolismo das amoras-pretas e com isso retardado a síntese dos flavonoides. Tal comportamento permite uma associação com a atividade da FAL, pois esta enzima está diretamente envolvida na síntese de compostos fenólicos (NAKAZAWA et al., 2001). Provavelmente, o AS atuou na redução da atividade do metabolismo primário e, consequentemente, no metabolismo secundário, pelo qual há a formação de flavonoides. Como houve a elevação dos níveis dos flavonoides após 96 horas nas concentrações acima de 1,0 mM, é possível sugerir que houve retardo no processo de maturação pela aplicação das maiores concentrações de AS. Em estudo com kiwis, Zhang et al. (2003) verificaram que a aplicação de AS inibiu a síntese de etileno, retardando o pico climatérico e atrasando a senescência.

Os resultados do teor de antocianinas demonstram que o AS interfere no processo de maturação dos frutos (Figura 3). Há diferença significativa no teor de antocianinas entre a testemunha e os tratamentos com AS na última avaliação (144horas), em que a testemunha apresentou maior teor de antocianinas em relação aos frutos tratados com AS.

Quando se faz uma avaliação conjunta dos dados, observa-se que o AS atua ativando mecanismos de defesa vegetal, pois observou-se alteração nos parâmetros bioquímicos, como na síntese de proteínas, atividade da $\beta$-1,3-glucanase, alteração na atividade da enzima FAL e na síntese de antocianinas e flavonoides. No entanto, os tratamentos com AS não interferiram diretamente sobre perda de biomassa, ATT, SST, ácido ascórbico e podridões, o que desperta para novos experimentos que considerem fatores como metabolismo respiratório e produção de etileno. Também há possibilidade de avaliação de frutos submetidos ao contato com algum patógeno em condições controladas, uma vez que a interação fruto-patógeno pode conduzir a indução de RSA (DANNER et al., 2008), e que sejam realizadas aplicações pré-colheita de AS nas plantas de amoreira-preta, conjugada à aplicação pós-colheita, as quais podem potencializar os efeitos de indução de RSA (CAPDEVILLE et al., 2003).

TABELA 1 - Atividade enzimática da quitinase (UAbs. $\mu$ g prot./mL $\left.\mathrm{mL}^{-1}\right)$ e $\beta-1,3$ glucanase $(\mu \mathrm{Glu} / \mathrm{min} / \mathrm{mg}$ proteína) presentes nos extratos de frutos de amora-preta cultivar Tupy tratada com diferentes concentrações de ácido salicílico. Dois Vizinhos - PR, 2013.

\begin{tabular}{lccccc}
\hline \multicolumn{1}{c}{ Tratamentos } & \multicolumn{5}{c}{ Avaliações bioquímicas enzimáticas } \\
\hline \multirow{2}{*}{ Quitinases } & 24 horas & 48 horas & 96 horas & 144 horas & Média \\
\cline { 2 - 6 } Testemunha & $0,012^{\text {ns }}$ & $0,014^{\text {ns }}$ & $0,010^{\text {ns }}$ & $0,012^{\text {ns }}$ & $0,011^{\text {ns }}$ \\
AS $(2,0 \mathrm{mM})$ & 0,011 & 0,011 & 0,012 & 0,014 & 0,012 \\
\hline$\beta \mathbf{1 , 3}$ Glucanase & \multicolumn{5}{c}{ UAlu.min $/ \mathrm{mg}_{\text {proteína }}{ }^{-1}$} \\
Testemunha & $0,024 \mathrm{aA}$ & $0,028 \mathrm{aA}$ & $0,030 \mathrm{bA}$ & $0,035 \mathrm{bA}$ & $0,024 \mathrm{aA}$ \\
AS $(2,0 \mathrm{mM})$ & $0,028 \mathrm{aB}$ & $0,029 \mathrm{aB}$ & $0,098 \mathrm{aA}$ & $0,095 \mathrm{aA}$ & $0,028 \mathrm{aB}$ \\
\hline
\end{tabular}

*Médias seguidas pela mesma letra maiúscula na linha e minúscula na coluna não diferem entre si, pelo teste de Tukey $(p \leq 0,05)$. ns=não significativo 


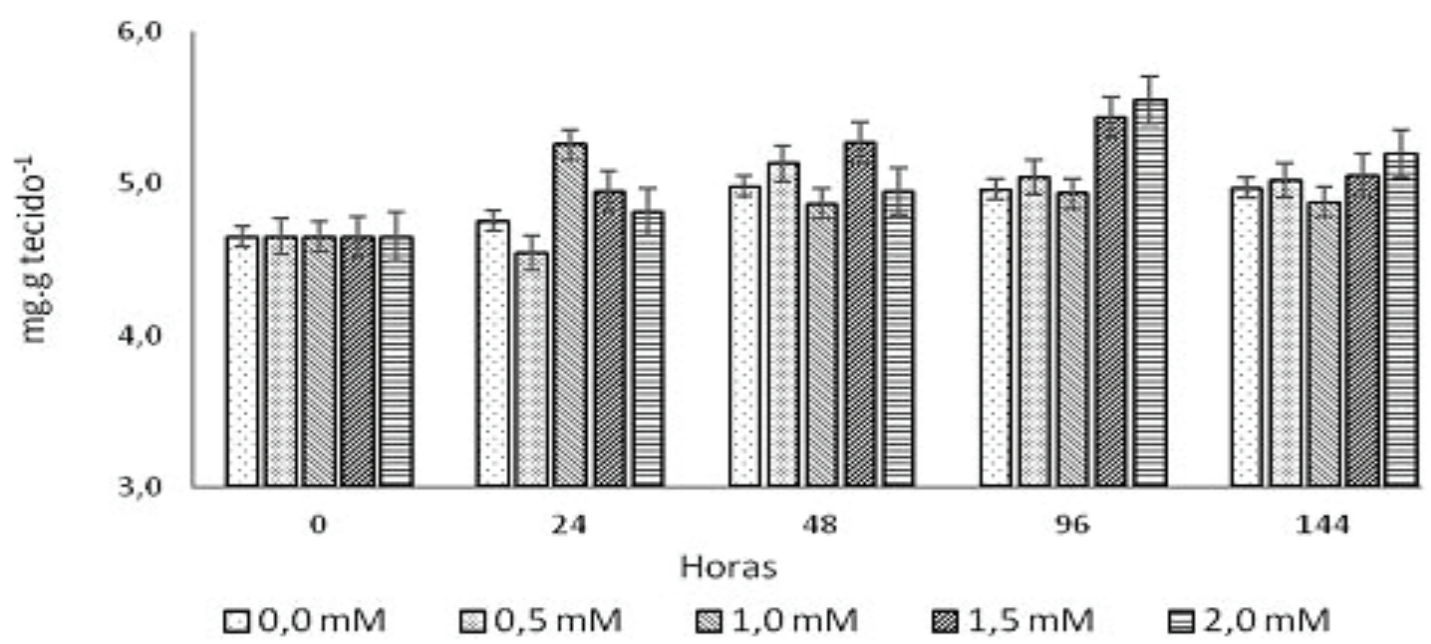

FIGURA 1- Teor de proteínas de amora-preta cultivar Tupy avaliada às 0; 24; 48; 96 e 144 horas após a aplicação de cinco concentrações de ácido salicílico. Barras verticais indicam o desvio-padrão. UTFPR. Dois Vizinhos - PR, 2013

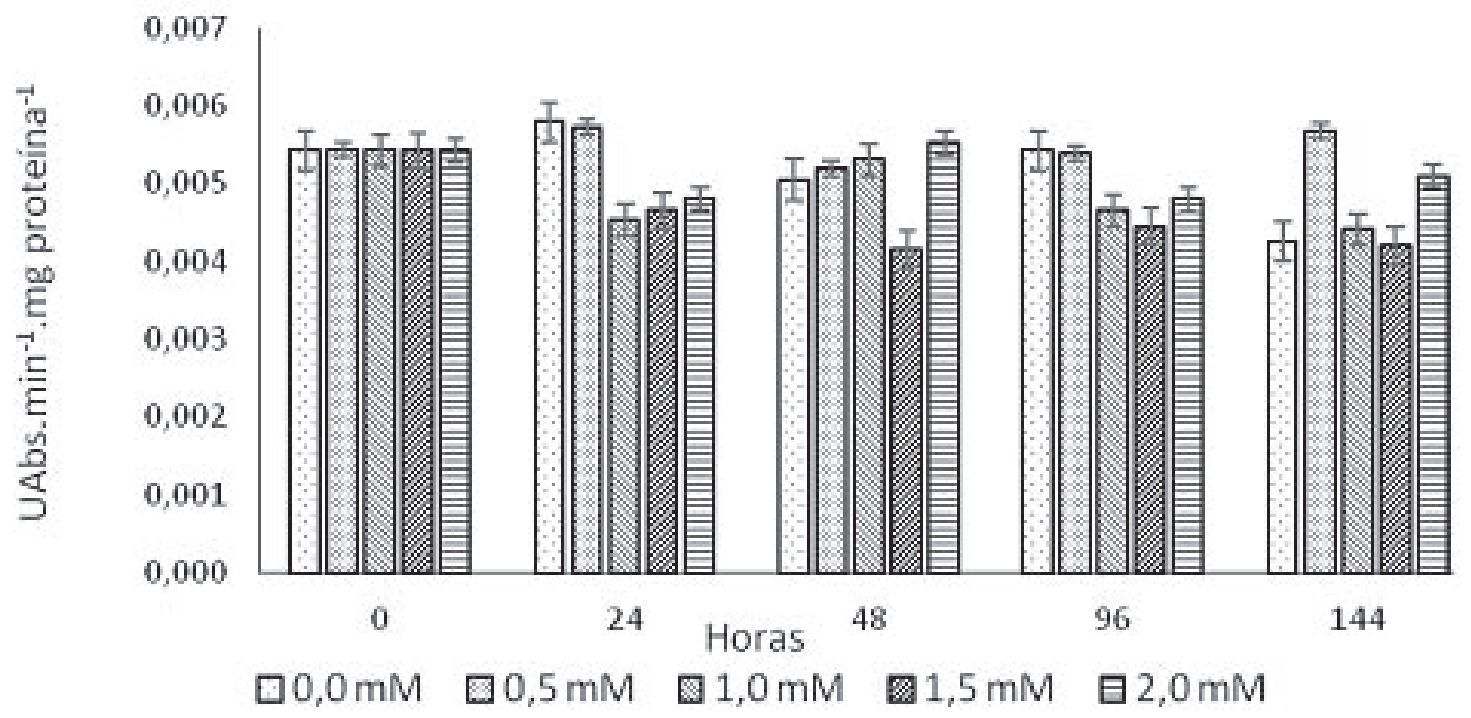

FIGURA 2- Atividade da enzima fenilalanina amônia-liase de amora-preta cultivar Tupy avaliada a 0;24; 48; 96 e 144 horas após a aplicação de cinco concentrações de ácido salicílico. Barras verticais indicam o desvio-padrão. UTFPR. Dois Vizinhos - PR, 2013. 

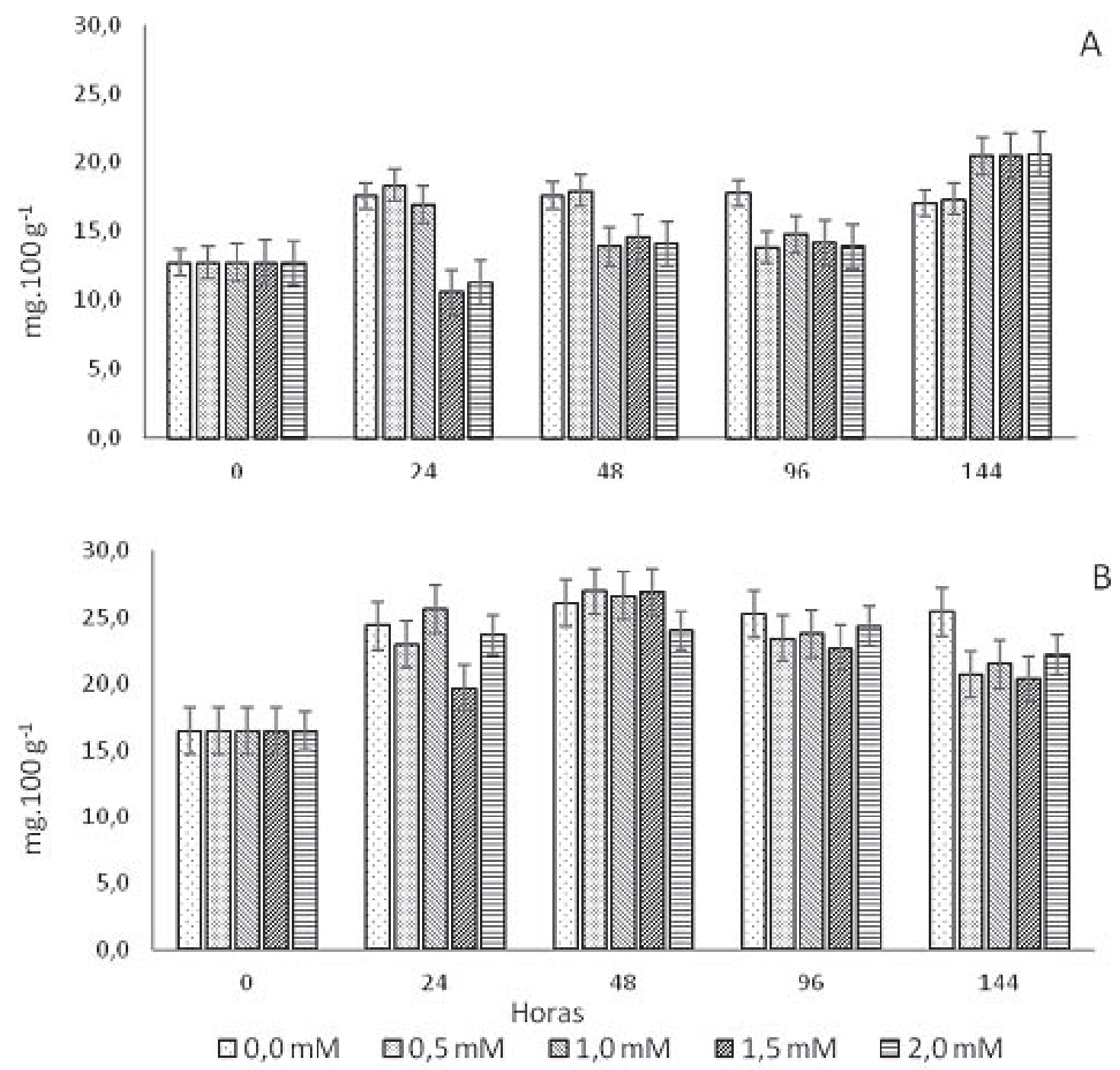

FIGURA 3- Teor de flavonoides (A) e antocianinas (B) de amora-preta cultivar Tupy avaliados as 0 ; 24; 48; 96 e 144 horas após a aplicação de cinco concentrações de ácido salicílico. Barras verticais indicam o desvio-padrão. UTFPR. Dois Vizinhos - PR, 2013.

\section{CONCLUSÕES}

A aplicação de ácido salicílico em póscolheita de amoras altera os níveis de proteínas totais e demonstra ativar rotas de defesa vegetal, como a PR-proteína $\beta$-1,3-glucanase e a rota dos fenilpropanoides, com alteração na atividade da fenilanina amônia-liase e compostos do metabolismo secundário, como antocianinas e flavonoides.

Os tratamentos com ácido salicílico não interferem nos parâmetros de perda de biomassa fresca, nos teores de acidez total titulável, nos sólidos solúveis totais e no ácido ascórbico, bem como na incidência de podridões e na atividade de quitinases.

\section{REFERÊNCIAS}

AMBORABE, B.E.; LESSARD, P.; CHOLLET, J.F.; ROBLIN, G. Antifungal effects of salicylic acid and other benzoic acid derivatives towards Eutypa lata: structure-activity relationship. Plant Physiology and Biochemistry, Poitiers, v.40, n.12, p.1051-1060, 2002.

ANTUNES, L.E.C.; DUARTE FILHO, J.; SOUZA, C.M. Conservação pós-colheita de frutos de amoreira-preta. Pesquisa Agropecuária Brasileira, Brasília, v.38, n.3, p.413-419, 2003. 
BRADFORD, M.M. A rapid and sensitive method for the quantitation of microgram quantities of protein utilizing the principle of protein-dye binding. Analytical Biochemistry, Athens, v.72, n.1/2, p.248254, 1976.

CAPDEVILLE, G.; BEER, S.V.; WATKINS, C.B.; WILSON, C.L.; TEDESCHI, L.O.; AIST, J.R. Preand post-harvest harpin treatments of apples induce resistance to blue mold. Plant Disease, Brasília, v.87, n.1, p.39-44, 2003.

CHEN, J.Y.; WEN, P.F.; KONG, W.F.; PAN, Q.H.; ZHANA, J.; LIA, J.M.; WAN, S.B. Effect of salicylic acid on phenylpropanoids and phenylalanine ammonia-lyase in harvested grape berries. Postharvest Biology and Technology, Amsterdam, v.40, n.1, p.64-72, 2006.

DANNER, M.A.; SASSO, S.A.Z.; MEDEIROS, J.G.S.; MARCHESE, J.A.; MAZARO, S.M. Indução de resistência à podridão-parda em pêssegos pelo uso de eliciadores em pós-colheita. Pesquisa Agropecuária Brasileira, Brasília, v.43, n.7, p.793799, 2008.

DURRANT, W.E.; DONG, X. Systemic acquired resistance. Annual Review of Phytopathology, Durham, v.42, p.185-209, 2004.

GRÜNER, R.; STROMPEN, G.; PFITZNER, A.P.; PFITZNER, U.M. Salicylic acid and the hypersensitive response initiate distinct signal transduction pathways in tobacco that converge on the as-1-like element of the PR-1a promoter. European Journal of Biochemistry, Stuttgart, v.270, n.24, p.4876-4886, 2003.

GUZZO, S.D.; MARTINS, E.M.F. Local and systemic induction of $\beta$-1,3-glucanase and chitinase in coffee leaves protected against Hemileia vastatrix by Bacillus thuringiensis. Journal of Phytopathology, Berlin, v.144, n.9/10, p.449-454, 1996.

INOCÊNCIO, A. P. M.; OLIVEIRA, M. B.; SANTOS, E. M.; NASCIMENTO, L. B.; ALVES, E. B.; SOARES, D. A.; LOBO JR., M.; SILVA, S. P. Indução de resistência em planta de feijoeiro infectada por Sclerotinia sclerotiorum. In: CONGRESSO BRASILEIRO DE MICROBIOLOGIA, 25., 2009, Porto de Galinhas. Resumos...
INSTITUTO ADOLFO LUTZ. Normas analíticas do Instituto Adolfo Lutz: Métodos físico-químicos para análise de alimentos. 4.ed. São Paulo, 2008.

JALALI, B.L.; BHARGAVA, S.; KAMBLE, A. Signal transduction and transcriptional regulation of plant defense responses. Journal of Phytopathology, Berlin, v.154, n.2, p.65-74, 2006.

KHADEMI, Z.; ERSHADI, A. Postharvest application of salicylic acid improves storability of peach (Prunus persica cv. Elberta) fruits. International Journal of Agriculture and Crop Sciences, London, v.5, n.6, p.651-655, 2013.

KUHN, O.J. Indução de resistência em feijoeiro (Phaseolus vulgaris) por acibenzolar-S-metil e Bacillus cereus: aspectos fisiológicos, bioquímicos e parâmetros de crescimento e produção. 2007. 140 f. Tese (Doutorado) - Escola Superior de Agricultura Luiz de Queiroz, Universidade de São Paulo, Piracicaba, 2007.

LEES, D.H.; FRANCIS, F.J. Standardization of pigment analyses in cranberries. HortScience, Alexandria, v.7, n.1, p.83-84, 1972.

LOLAEI, A.; KAVIANI, B.; REZAEI, M.A.; RAAD, M.K.; MOHAMMADIPOUR, R. Effect of pre- and postharvest treatment of salicylic acid on ripening of fruit and overall quality of strawberry (Fragaria ananasa Duch cv. Camarosa) fruit. Annals of Biological Research, Uadipur,v.3, n.10, p.46804684, 2012.

NAKAZAWA, A.; NOZUE, M.; YASUDA, H.; TAKEDA, G.; KUBO, H. Expression pattern and gene structure of phenylalanine ammonia-lyase in Pharbitis nil. Journal of Plant Research, Tokyo, v.114, n.3, p.323-328, 2001.

PICOLI, A.A.; FARIA, D.F.; JOMORI, M.L.L.; KLUGE, R.A. Avaliação de biorreguladores no metabolismo secundário de beterrabas inteiras e minimamente processadas. Bragantia, Campinas, v.69, n.4, p.983-988, 2010. 
RASEIRA, M.C.B.; SANTOS, A.M.; BARBIERI, R.L. Classificação botânica, origem e cultivares. In: EMBRAPA.Sistema de produção da amoreira-preta. 2008. Disponível em: $<\underline{\text { http://sistemasdeproducao. }}$ cnptia.embrapa.br/FontesHTML/Amora/ SistemaProducaoAmoreiraPreta/botanica.htm $>$ Acesso em: 04 nov. 2013.

S A L ARI, N.; B AHR A MINEJAD, A.; AFSHARMANESH, G.; KHAJEHPOUR, G. Effect of salicylic acid on post-harvest quantitative and qualitative traits of strawberry cultivars. Advances in Environmental Biology, New Delhi, v.7, n.1, p.94-99, 2012.

SAYARI, M.; BABALAR, M.; KALANTARI, S.; ALIZADEH, H.; ASGARI. M.A. Effect of salicylic acid on chilling resistance and phenylalanine ammonia lyase activity in pomegranate cultivars Mals Saveh in storage. Iranian Journal of Horticultural Sciences, Daneshkade, v.40, n.3, p.21-28, 2009.

SILVA, F. A. S.; AZEVEDO, C. A. V. Principal Components Analysis in the Software AssistatStatistical Attendance. In: WORLD CONGRESS ON COMPUTERS IN AGRICULTURE, 7., 2009. Proceedings... Reno: American Society of Agricultural and Biological Engineers, 2009.
VIZZOTTO, M.; RASEIRA, M.C.B.; PEREIRA, M.C.; FETTER, M.R. Teor de compostos fenólicos e atividade antioxidante em diferentes genótipos de amoreira-preta (Rubus sp.). Revista Brasileira de Fruticultura, Jaboticabal, v.34, n.3, p.853-858, 2012.

VLOT, A.C.; DEMPSEY, D.A.; KLESSIG, D.F. Salicylic acid, a multifaceted hormone to combat disease. Annual Review of Phytopathology, Palo Alto, v.47, p.177-206, 2009.

ZHANG, Y.; CHEN, K.; ZHANG, S.; FERGUSON, I. The role of salicylic acid in postharvest ripening of kiwifruit. Postharvest Biology and Technology, Amsterdam, v.28, p.64-74, 2003.

WESSELS, J.G.H.; SIETSMA, J.H. Fungal cell walls: a survey. In: TANNER, W.; FA LOEWUS, F.A. (Ed.). Encyclopedia of plant physiology: plant carbohydrates. Berlin: Springer, 1981.v.138, p.352-394.

WIRTH, S.J.; WOLF, G.A. Micro-plate colourimetric assay for endo-acting cellulose, xylanase, chitinase, 1,3- $\beta$-glucanase and amylase extracted from forest soil horizons. Soil Biology and Biochemistry, Oxford, v.24, p.511-519, 1992. 